\title{
ARTICLE
}

\section{Effect of atmosphere on the vaporization behavior of $\mathrm{CsFeSiO}_{4}$}

\author{
Eriko Suzuki*, Kunihisa Nakajima and Masahiko Osaka \\ Japan Atomic Energy Agency, 2-4 Shirakata, Tokai-mura, Naka-gun, Ibaraki-ken, 319-1195, Japan
}

\begin{abstract}
Effects of atmospheres on the vaporization behavior of $\mathrm{Cs}$ chemisorbed compound $\mathrm{CsFeSiO}_{4}$ was experimentally investigated. A pure $\mathrm{CsFeSiO}_{4}$ sample was synthesized by a powder metallurgical route and was subjected to the thermogravimetric analysis. Weight loss of $\mathrm{CsFeSiO}_{4}$ was larger in the order of those under Ar-5 \% $\mathrm{H}_{2}$ and Ar-5 \% $\mathrm{H}_{2} \mathrm{O}-5 \% \mathrm{H}_{2}, \mathrm{Ar}-5 \% \mathrm{H}_{2} \mathrm{O}$, Ar and air. This would correspond to the varied vapor pressures of $\mathrm{CsFeSiO}_{4}$ by different oxygen potentials in the atmospheres. On the other hand, larger weight losses under $\mathrm{H}_{2}$ containing atmospheres were observed regardless of the oxygen potential. An X-ray diffraction analysis and a chemical equilibrium calculation have indicated the possible decomposition of $\mathrm{CsFeSiO}_{4}$ by the interaction with $\mathrm{H}_{2}$ in the vapor phase.
\end{abstract}

Keywords: cesium; chemisorption; $\mathrm{CsFeSiO}_{4}$; revaporization; atmosphere; thermogravimetry

\section{Introduction}

The Cs chemisorption phenomena under an LWR severe accident (SA) is of crucial importance especially for the determination of debris removal strategy from Fukushima Daiichi Nuclear Power Station (1F), since chemisorbed Cs can become a major long-term radiation source. We have therefore conducted an experimental test series CREST (Chemical REaction with stainless STeel) for the investigation of the Cs chemisorption with a focus on the chemical behavior of Cs chemisorbed compounds [1,2]. A test for the investigation of atmospheric effects on the Cs chemisorption (CREST-ATM) has shown the atmospheric dependence of revaporization for the main $\mathrm{Cs}$ chemisorbed compound on the stainless steel (SS) surface, $\mathrm{CsFeSiO}_{4}$ [3]. Namely, only Cs was revaporized from the Cs chemisorbed compound $\mathrm{CsFeSiO}_{4}$ on the SS surface after a heating at $1073 \mathrm{~K}$ under a Cs-absent reductive atmosphere $\left(\mathrm{Ar}-5 \% \mathrm{H}_{2}\right)$, while $\mathrm{Si}$ remained on the SS surface. It was inferred that possible decomposition of $\mathrm{CsFeSiO}_{4}$ at $1073 \mathrm{~K}$ has taken place by the interaction with $\mathrm{H}_{2}$ in the vapor phase. This revaporization phenomena should be accurately known for the evaluation of the Cs chemisorption.

In this study, effects of atmosphere on the revaporization of $\mathrm{CsFeSiO}_{4}$ was experimentally investigated. A pure $\mathrm{CsFeSiO}_{4}$ sample was synthesized for the thermogravimetric analysis (TGA) in order to know the vaporization behavior. Characterization of the samples after the TGA together with a chemical equilibrium calculation was carried out for the

*Corresponding author. Email: suzuki.eriko@jaea.go.jp discussion of the chemical reaction occurred in relation with the revaporization.

\section{Experimental and calculation}

Table 1 shows the experimental conditions for the sample synthesis, TGA and characterization after the TGA. Details are described below.

Table 1. Experimental conditions for the Cs revaporization and characterization tests.

\begin{tabular}{|c|c|}
\hline \multicolumn{2}{|l|}{ Synthesis of $\mathrm{CsFeSiO}_{4}$} \\
\hline Starting materials & $\begin{array}{l}\mathrm{Cs}_{2} \mathrm{CO}_{3}, \mathrm{Fe}_{2} \mathrm{O}_{3} \text { and } \mathrm{SiO}_{2}, \\
\mathrm{Cs}: \mathrm{Fe}: \mathrm{Si}=1.4: 1.0: 1.0\end{array}$ \\
\hline Heat treatment & 1073 to $1273 \mathrm{~K}, 9 \mathrm{~h}$ \\
\hline \multicolumn{2}{|c|}{ Thermogravimetric analysis (TGA) } \\
\hline Temperature & $\begin{array}{l}1573 \mathrm{~K} \text { (holding time: } 1 \mathrm{~min} . \\
\text { heating rate: } 20 \mathrm{~K} / \mathrm{min} .)\end{array}$ \\
\hline Atmosphere & $\begin{array}{l}\text { Air, Ar, Ar-5 \% } \mathrm{H}_{2} \mathrm{O} \text {, } \\
\text { Ar-5 } \% \mathrm{H}_{2} \mathrm{O}-5 \% \mathrm{H}_{2}, \text { Ar- } 5 \% \mathrm{H}_{2}\end{array}$ \\
\hline \multicolumn{2}{|l|}{ Characterization } \\
\hline $\begin{array}{l}\text { Heat treatment } \\
\text { condition for samples } \\
\text { simulated the post TGA } \\
\text { X-Ray diffractometry } \\
\text { Chemical equilibrium } \\
\text { calculation }\end{array}$ & $\begin{array}{l}\mathrm{CsFeSiO}_{4} \text {, heated at } 1073 \mathrm{~K} \text {, } \\
\text { under } \mathrm{Ar}-5 \% \mathrm{H}_{2} \mathrm{O}-5 \% \mathrm{H}_{2} \text { or } \\
\mathrm{Ar}-5 \% \mathrm{H}_{2} \\
\mathrm{CuK} \alpha, 40 \mathrm{kV}, 15 \mathrm{~mA} \\
\text { Corresponding elemental moles } \\
\text { to CsFeSiO } \\
\text { database, under } \\
\text { Ar-5 } \% \mathrm{H}_{2} \mathrm{O}-5 \% \mathrm{H}_{2}, \mathrm{Ar}-5 \% \mathrm{H}_{2}\end{array}$ \\
\hline
\end{tabular}

A pure $\mathrm{CsFeSiO}_{4}$ sample was synthesized by a heat treatment of a mixed powder of each starting material. The starting materials of $\mathrm{Cs}_{2} \mathrm{CO}_{3}, \mathrm{Fe}_{2} \mathrm{O}_{3}$ and $\mathrm{SiO}_{2}$ compounds with a molar ratio of $\mathrm{Cs}: \mathrm{Fe}: \mathrm{Si}=1.4: 1.0$ : 1.0 were intimately mixed in an agate mortar with a 
pestle. The mixed powder was compacted into a columnar shaped pellet for the heat treatment. The heat treatment was carried out in a static air repeatedly at $1073 \mathrm{~K}$ for $5 \mathrm{~h}$, at $1173 \mathrm{~K}$ for $2 \mathrm{~h}$ and $1273 \mathrm{~K}$ at $2 \mathrm{~h}$. The heat-treated mixed powders were then characterized by an X-ray diffractometer (XRD).

The TGA of the synthesized $\mathrm{CsFeSiO}_{4}$ sample was carried out by using a RIGAKU model Thermo-plus EVO2 and $\mathrm{Al}_{2} \mathrm{O}_{3}$ crucibles. TGA were carried out at a heating rate of $20 \mathrm{~K} / \mathrm{min}$. up to $1573 \mathrm{~K}$, temperature held for $1 \mathrm{~min}$. before decreasing the temperature. Five kinds of atmosphere were applied for the TGA, specifically Air, Ar, Ar-5 \% $\mathrm{H}_{2} \mathrm{O}$, Ar-5 \% $\mathrm{H}_{2} \mathrm{O}-5 \% \mathrm{H}_{2}$ and Ar-5 \% $\mathrm{H}_{2}$. The last two atmospheres were the same as in the CREST-ATM test in which the revaporization of $\mathrm{CsFeSiO}_{4}$ were observed.

The XRD was done on the $\mathrm{CsFeSiO}_{4}$ samples after the heat treatment at $1073 \mathrm{~K}$ for $1 \mathrm{~h}$ in another heating furnace in the corresponding atmosphere to the TGA. As shown later, since a notable gravimetric difference during TGA and preferable Cs loss under Ar-5\% $\mathrm{H}_{2}$ in the CREST-ATM were observed at this temperature of $1073 \mathrm{~K}$, this heat treatment was carried out for the detailed investigation on what kind of chemical reaction has taken place. A chemical equilibrium calculation as the corresponding condition to this experimental observation at $1073 \mathrm{~K}$ was also carried out for the discussion of the chemical reactions taken place. In the calculation, each elemental fraction was set so as to correspond to the $1 \mathrm{~mol}$ of $\mathrm{CsFeSiO}_{4}$ under atmospheres of Ar-5 \% $\mathrm{H}_{2} \mathrm{O}-5 \% \mathrm{H}_{2}$ or Ar-5 $\% \mathrm{H}_{2}$.

\section{Results and discussion}

Figure 1 and Table 2 show XRD pattern and determined lattice parameters of the synthesized sample, respectively. Since almost all the peaks match the reference peaks and the lattice parameters agree with the reference ones with experimental errors, a pure $\mathrm{CsFeSiO}_{4}$ sample is considered to be successfully obtained.

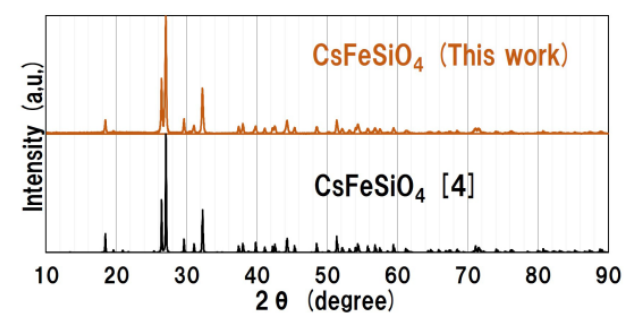

Figure 1. X-ray diffraction patterns of synthesized $\mathrm{CsFeSiO}_{4}$ sample and reference [4].

Table 2. Determined lattice parameters of synthesized $\mathrm{CsFeSiO}_{4}$ sample

\begin{tabular}{lll}
\hline \multicolumn{3}{l}{ Lattice parameter [m] } \\
\hline & Henry [4] & This work \\
\hline $\mathrm{a} / \AA$ & $9.5858(4)$ & $9.5833(42)$ \\
$\mathrm{b} / \AA$ & $5.5538(3)$ & $5.5552(26)$ \\
$\mathrm{c} / \AA$ & $9.0476(4)$ & $9.0501(35)$ \\
\hline
\end{tabular}

Figure 2 shows the TGA results for $\mathrm{CsFeSiO}_{4}$ under the five different atmospheres. The common feature for all atmospheres was observed above around $1373 \mathrm{~K}$; namely acceleration of weight loss compared to that under $1373 \mathrm{~K}$. This feature could correspond to a phase transition or decomposition of $\mathrm{CsFeSiO}_{4}$, or some chemical reactions at around this temperature, although presently no information is available for the phase states at such high temperature for $\mathrm{CsFeSiO}_{4}$.

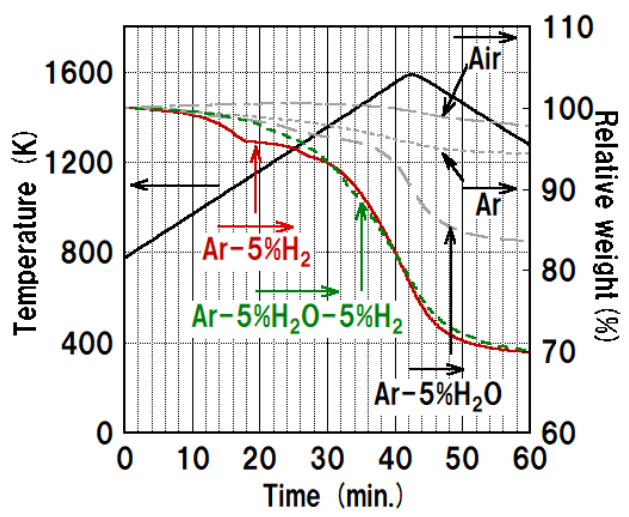

Figure 2. TGA of $\mathrm{CsFeSiO}_{4}$ under the different atmospheres.

Weight losses at the end of the TGA (60 min.) are larger in the order of those under $\mathrm{Ar}-5 \% \mathrm{H}_{2}$ and Ar-5 $\% \mathrm{H}_{2} \mathrm{O}-5 \% \mathrm{H}_{2}$, Ar-5 $\% \mathrm{H}_{2} \mathrm{O}$, Ar and air. One possible reason for this would be caused by increase of vapor pressures with decrease of the oxygen potential in the atmosphere.

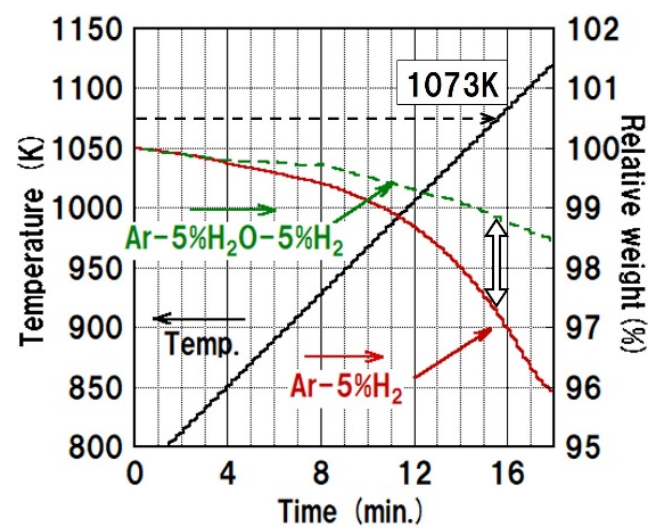

Figure 3. TGA of $\mathrm{CsFeSiO}_{4}$ under $\mathrm{Ar}-5 \% \mathrm{H}_{2} \mathrm{O}-5 \% \mathrm{H}_{2}$ and Ar-5 $\% \mathrm{H}_{2}$; enlargement of the TGA graph shown in Figure 2 up to $1123 \mathrm{~K}$.

Of note is the almost similar weight loss profiles of Ar-5 $\% \mathrm{H}_{2}$ and of Ar-5 $\% \mathrm{H}_{2} \mathrm{O}-5 \% \mathrm{H}_{2}$ regardless of difference of oxygen potential. This implies possible dominant effects of $\mathrm{H}_{2}$ in the atmosphere, rather than the effects by the difference in the oxygen potential. Namely, some interaction of $\mathrm{H}_{2}$ with $\mathrm{CsFeSiO}_{4}$ could have taken place, to have made the weight losses profiles similar. However, it can be seen that the weight loss profiles are distinctly different between under these two atmosphere at around $1073 \mathrm{~K}$. In CREST tests, Cs revaporization from $\mathrm{CsFeSiO}_{4}$ has occurred under reductive atmosphere 
$\left(\right.$ Ar-5 \% $\left.\mathrm{H}_{2}\right)$ at $1073 \mathrm{~K}$. As shown in the TGA profiles enlarged around this temperature (Figure 3), the weight loss is larger in Ar-5 \% $\mathrm{H}_{2}$ compared to that in Ar-5 \% $\mathrm{H}_{2} \mathrm{O}-5 \% \mathrm{H}_{2}$. This difference implies a possible suppression of the interaction between $\mathrm{H}_{2}$ and $\mathrm{CsFeSiO}_{4}$ under the Ar-5 \% $\mathrm{H}_{2} \mathrm{O}-5 \% \mathrm{H}_{2}$.

Figure 4 shows the XRD patterns of the simulant $\mathrm{CsFeSiO}_{4}$ samples. As mentioned above, these samples were prepared by the heat treatment of synthesized $\mathrm{CsFeSiO}_{4}$ at $1073 \mathrm{~K}$ for $1 \mathrm{~h}$ to simulate those experienced the TGA at that temperature.

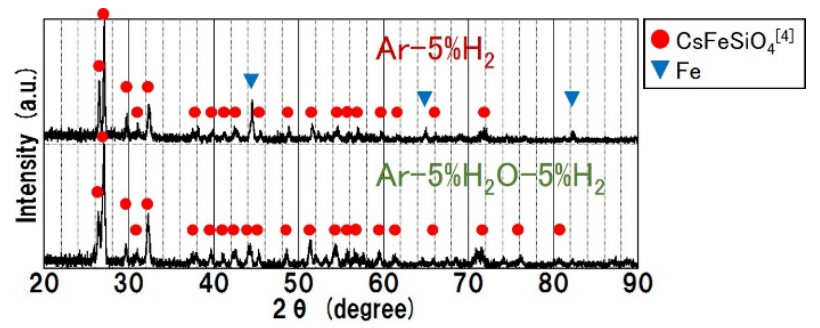

Figure 4. X-ray diffraction patterns of $\mathrm{CsFeSiO}_{4}$ samples heat treated under $\mathrm{Ar}-5 \% \mathrm{H}_{2} \mathrm{O}-5 \% \mathrm{H}_{2}$ or $\mathrm{Ar}-5 \% \mathrm{H}_{2}$ at $1073 \mathrm{~K}$.

The bcc (body centered cubic) -Fe peaks were clearly observed in addition to those derived from $\mathrm{CsFeSiO}_{4}$ on the sample heat treated under Ar-5 \% $\mathrm{H}_{2}$, while no bcc-Fe peaks were seen under $\mathrm{Ar}-5 \% \mathrm{H}_{2} \mathrm{O}-5 \% \mathrm{H}_{2}$. This indicates a possible decomposition of $\mathrm{CsFeSiO}_{4}$ by the heat treatment under Ar-5\% $\mathrm{H}_{2}$. Although only Cs loss with leaving $\mathrm{Si}$ was observed in the CREST-ATM, Si compounds-derived peaks, such as those from $\mathrm{SiO}_{2}$ which has amorphous structure, were not observed in the XRD peaks. Nevertheless, the chemical equilibrium calculation results show the formation of bcc-Fe and $\mathrm{SiO}_{2}$ under these conditions of $1073 \mathrm{~K}$ in $\mathrm{Ar}-5 \% \mathrm{H}_{2}$. From the results mentioned above, it is inferred that the low temperature accelerated decomposition of $\mathrm{CsFeSiO}_{4}$ at around $1073 \mathrm{~K}$ under $\mathrm{Ar}-5 \% \mathrm{H}_{2}$ can be expressed by the following equation.

$$
\begin{aligned}
& \mathrm{CsFeSiO}_{4}(\mathrm{~s})+\frac{3}{2} \mathrm{H}_{2}(\mathrm{~g}) \\
& \quad=\mathrm{CsOH}(\mathrm{g})+\mathrm{Fe}(\mathrm{s})+\mathrm{SiO}_{2}(\mathrm{~s})+\mathrm{H}_{2} \mathrm{O}(\mathrm{g}) \\
& \text { or } \quad \text { (1) } \\
& \mathrm{CsFeSiO}_{4}+2 \mathrm{H}_{2}=\mathrm{Cs}(\mathrm{g})+\mathrm{Fe}(\mathrm{s})+\mathrm{SiO}_{2}+2 \mathrm{H}_{2} \mathrm{O}(\mathrm{g})
\end{aligned}
$$

\section{Conclusion}

An experimental investigation of the effects of atmosphere on the vaporization behavior of Cs chemisorbed compounds $\mathrm{CsFeSiO}_{4}$ was performed. It was found that the weight loss was larger when the oxygen potential was lower. Of note is the greater weight loss of $\mathrm{CsFeSiO}_{4}$ under $\mathrm{H}_{2}$ including atmospheres regardless of $\mathrm{H}_{2} \mathrm{O}$ inclusion. Besides, the accelerated weight loss was observed at $1073 \mathrm{~K}$ only under $\mathrm{Ar}-5 \% \mathrm{H}_{2}$. It is inferred that $\mathrm{H}_{2}$ plays an important role for the enlarged weight loss of Cs chemisorbed compound $\mathrm{CsFeSiO}_{4}$ by the decomposition.

As the $\mathrm{H}_{2}$ generation absolutely occurred in the LWR SA progress by the oxidation of fuel cladding and structural materials, the present result is important for the accurate estimation of Cs chemisorption in the LWR under and after SA.

\section{Acknowledgements}

Mr. K. Ebata and Mr. J. Takada are greatly appreciated for their helpful support to the experiment.

\section{References}

[1] F.G.Di Lemma, K. Nakajima, S. Yamashita and M. Osaka, Surface analyses of cesium hydroxide chemisorbed onto type 304 stainless steel, J. Nucl. Eng. Des. 305 (2016), pp. 411-420.

[2] F.G.Di Lemma, K. Nakajima, S. Yamashita and M. Osaka, Experimental investigation of the influence of Mo contained in stainless steel on Cs chemisorption behavior, J. Nucl. Mater. 484 (2017), pp. 174-182.

[3] K. Nakajima, E. Suzuki and M. Osaka, Atmospheric effect on Cs chemisorption behaviors onto stainless steel, Prog. Nucl. Sci. Technol. 5 (2018), pp.168-170.

[4] P.F. Henry and M.T. Weller, $\mathrm{CsFeSiO}_{4}$ : a maximum iron content zeotype, Chem. Commun. 24 (1998), pp. 2723-2724. 